\title{
A multimedia-based cognitive-behavioural intervention program improves attitudes and handling behaviours of stockpeople in livestock farming
}

\author{
M.A.W. Ruis ${ }^{1}$, G.J. Coleman ${ }^{2}$, S. Waiblinger ${ }^{3}$, I. Windschnurer ${ }^{3}$, X. Boivin ${ }^{4}$
}

${ }^{1}$ Wageningen UR Livestock Research, Lelystad, Netherlands, ${ }^{2}$ Monash University, Clayton, Australia, ${ }^{3}$ Institute of Animal Husbandry and Welfare, Vienna, Austria, ${ }^{4}$ INRA de Clermont-Ferrand-Theix, St-Genès Champanelle, France

Email:marko.ruis@wur.nl

Introduction The amount and quality of human-animal interactions were shown to strongly affect animal welfare and productivity of several farm animal species via the strength of positive or negative (e.g. fear) emotions involved in the perception of humans (for review: Hemsworth and Coleman, 1998). In a recent survey on Dutch pig farms it was shown that in general, a negative attitude is associated with rough or aversive handling practices, whereas more positive ideas on handling are linked with more quiet and gentle handling practices (Visser et al., 2006). Such relationships between attitudes of stockpeople and their behaviour towards animals have now been shown in several species, and several studies also show a subsequent relation with the behavioural response of the animals to humans and their productivity (e.g. in cattle: Waiblinger et al., 2002). In Australia and United States, cognitive-behavioural intervention programmes have been designed to specifically target key attitudes and behaviours of stockpeople. These training programmes have produced substantial improvements in the attitude and behaviour of stockpeople and a marked reduction in the level of fear of humans by pigs and cattle (e.g. Coleman et al., 2000). Based on the Australian experiences, within Welfare Quality ${ }^{\circledR}$ the multimedia training program 'Quality Handling' was developed specifically for the European context. The present study investigated whether this training improved attitude and behaviour of European stockpeople towards their animals, and also changed behavioural and fear responses of the animals.

Materials and methods Three species were involved: cattle, pigs and laying hens. Following development of the training packages, their effectiveness in achieving changes in attitudes and behaviour of stockpeople was tested in field tests. The field tests were carried out in The Netherlands (laying hens and pigs), and Austria (dairy cattle). Stockpeople were randomly allocated to training groups (dairy cattle: 10 farms, 14 people; pigs: 8 farms, 12 people; laying hens: 7 farms, 10 people) or control groups (dairy cattle: 9 farms, 9 people; pigs: 9 farms, 12 people; laying hens: 8 farms, 11 people). All farms were visited twice. Only stockpeople of the training group were trained, within 2 weeks after the first visit. The period between the two visits was approximately 6-8 weeks. Human attitudes towards animals were determined by means of a questionnaire filled in during the visits. Average scores were obtained for beliefs about animal characteristics (general attitude) and handling situations (behavioural attitude). Stockpeoples' behaviour was assessed by means of behavioural observations during handling, and expressed in \% of positive behaviours per unit or animal. Finally, the animal's avoidance behaviour to the approach of an unfamiliar person was measured to assess fear for humans.

Results To analyze the results of the field tests, a combined analysis was performed for the three species with stockperson as the replicate. Sixty four stockpeople participated although some missing data resulted in varying sample sizes for the analyses. Data were first standardized within each species to remove the effects of the species-specific units of measurement of each variable. Data were analyzed by a 3 (species) by 2 (treatment group) analysis of covariance with the post training score as the dependent variable and the pre training score as the covariate. There was a significant increase in positive general attitude $(\mathrm{F} 1,57=4.77, \mathrm{p}<0.05)$ and in positive behavioural attitude towards animals under care $(\mathrm{F}$ $1,57=7.03, p<0.01$ ) for the trained group compared to the control group. Moreover, the percentage of positive behaviours towards animals under care increased significantly in the trained group compared to the controls $(\mathrm{F} 1,49=9.48, \mathrm{p}<.01)$. The training did not significantly affect avoidance behaviour upon human approach (F 1,43=3.52, $\mathrm{p}=.07)$.

Conclusions The results demonstrate that the multimedia training program 'Quality Handling' is a promising tool to improve the attitudes and handling behaviours of stockpeople in European livestock farming. The period between the training and second visit may have been too short to result in an effect on animal fear and behaviour. The training packages were finalized in 2009 and are now available for training sessions in English (pig and laying hen programmes also in Dutch; cattle program also in French and German).

Ackowledgements The study was supported by the European research project Welfare Quality ${ }^{\circledR}$, and co-financed by the European Commission within the 6th Framework Programme, contract no. FOOD-CT-2004-506508. For development and testing of the training packages for pig and laying hen stockpeople, funding was also obtained from the Dutch Ministry of Agriculture, Nature and Food Quality.

References Coleman, G.J., Hemsworth, P.H., Hay, M., Cox, M. 2000. Modifying stockperson attitudes and behaviour towards pigs at a large commercial farm. Applied Animal Behaviour Science 66, 11-20.

Hemsworth, P.H., and Coleman, G.J. 1998. Human-livestock interactions: The stockperson and the productivity of intensively farmed animals. CAB International, Wallingford, UK.

Visser, E.K., Kiezebrink, M.C., Vermeer, H.M., Mul, M., Altena, H, Spoolder, H.A.M. 2006. Dutch farmers' perspective on human-pig contact and handling. Welfare Quality ${ }^{\mathbb{B}}$, deliverable 3.4, subtask 3.1.1.3.

Waiblinger, S., Menke, C., Coleman, G. 2002. The relationship between attitudes, personal characteristics and behaviour of stockpeople and subsequent behaviour and production of dairy cows. Applied Animal Behaviour Science 79, 195-219.

Waiblinger S., C.Menke, G. Coleman (2002): The relationship between attitudes, personal characteristics and behaviour of stockpeople and subsequent behaviour and production of dairy cows. Applied Animal Behaviour Science 79(3), 195-219. 